\title{
A Review on "Prevention of Emitter Clogging in Drip Irrigation System with the Help of Tube Settlers"
}

\author{
Jayesh Tatiya ${ }^{[1]}$ \\ [1] Graduation student, \\ Department of Civil Engineering, \\ Pimpri Chinchwad College of Engineering and Research, \\ Maharashtra, India. \\ Shyam Karhale ${ }^{[2]}$ \\ [2] Graduation student, \\ Department of Civil Engineering, \\ Pimpri Chinchwad College of Engineering and Research, \\ Maharashtra, India.
}

\author{
Balaji Khurde [3] \\ [3] Graduation student, \\ Department of Civil Engineering, \\ Pimpri Chinchwad College of Engineering and Research, \\ Maharashtra, India. \\ Krishna Hulsure ${ }^{[4]}$ \\ [4] Graduation student, \\ Department of Civil Engineering, \\ Pimpri Chinchwad College of Engineering and Research, \\ Maharashtra, India.
}

\author{
G. N. Supe ${ }^{[5]}$ \\ [5] Assistant Professor, \\ Department of Civil Engineering, \\ Pimpri Chinchwad College of Engineering and Research, \\ Maharashtra, India.
}

\begin{abstract}
In areas of small rainfall or jagged rain sharing water conservation is vital to maintain agricultural production. Particularly in water shortage area to maintain to overcome the paucity of water and maintaining economic production of various crops surface and sub-surface irrigation plays a momentous role under this situation. One of the most important factors that affect the performance on drip irrigation system is emitter clogging. Emitter clogging not only negatively influences uniformity of water distribution but also causes inadequate irrigation which directly affects the crop quality and quantity. Emitter clogging is directly related to irrigation water quality, which is the function of physical chemical and biological constituents of irrigation water. It's more beneficial if we control the water quality at the entrance of the drip irrigation network. This study will mainly focus on the physical constituents of irrigation water that causes clogging of emitters of drip irrigation system. Sedimentation is a physical treatment process that utilizes gravity to separate suspended solids from water. Tube settlers are multiple tubular channels sloped at a certain angle which increases the settling area and thus decreasing the detention time from hours to minutes. The present study is aimed to prevent emitter clogging in drip irrigation system by caused by physical constituents of irrigation water. A pilot scale model of sedimentation tank with tube settlers is prepared. The detention time reduced up to $20 \mathrm{~min}$ which is very less compared to conventional sedimentation tank. There is an average $\mathbf{7 0 - 8 0 \%}$ removal in turbidity
\end{abstract}

Key Words: Sedimentation, drip irrigation, emitter clogging, tube settler.

\section{INTRODUCTION}

India is amongst the largest irrigated lands in the world, but has one of the lowest per-capita as well as per hectare availability of water. The key for improving agricultural production and productivity in the country is efficient and judicious use of water and fertilizers. In India due to various reasons demand for water for different purposes has been continuously increasing at an alarming rate, but potential water availability for the future is declining. The major water consuming Sector in India is the agricultural sector (irrigation) which currently consumes over 80 percent of available water in India. Hence to maximize the yield the available water should be used very effectively through water saving irrigation technologies due to unavailability and water scarcity. Commonly furrow and basin irrigation methods are used which causes adverse effects of water excess and water stress.

One of the most efficient technologies in irrigation is Drip Irrigation. It supplies precise amount of water directly to the root zone of the crop at right time. It also matches with the consumptive water demand of plant for optimum growth, better yield and good quality of produce. It is estimated that around 12-84 percent of water is saved in different crops. It refers to frequent application of water in drops at the root zone of the crops.

One of the most important factors that affect the performance of the drip irrigation system is emitter clogging. Emitter clogging which is formed in short time due to irrigation systems running inadequate pressure not only causes inadequate irrigation but also influences uniformity of water distribution. Emitter clogging is directly related to irrigation water quality, which is the function of physical, chemical and biological constituents of irrigation water. The most common physical constituents 
are the common silt and clay and various organic matter that are in suspension in the water. Basically the Total Suspended Solids (TSS) is the most common physical parameters. The common Chemical Constituents are dissolved calcium, bicarbonates, salts, iron, manganese, etc. The biological parameters are the various bacteria's that grow in the water both aerobic and anaerobic.

Table no. 1 Physical, chemical, biological factors involved in emitter clogging

\begin{tabular}{|c|c|c|}
\hline Physical & Chemical & Biological \\
\hline 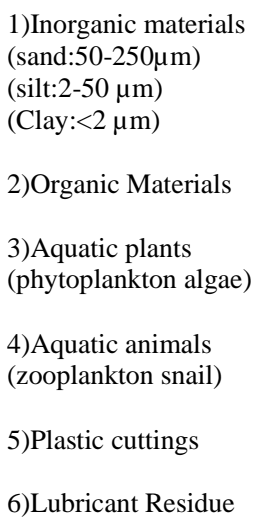 & $\begin{array}{l}\text { 1) Alkaline Earths } \\
\text { (Heavy metals, } \\
\text { cations, calcium, } \\
\text { magnesium, iron, } \\
\text { manganese) } \\
\text { 2) Anions } \\
\text { (carbonate, } \\
\text { hydroxide, silicate, } \\
\text { sulfide) } \\
\text { 3) Fertilizer Sources } \\
\text { (aqueous ammonia, } \\
\text { iron, copper, zinc, } \\
\text { manganese, } \\
\text { phosphorus ) }\end{array}$ & $\begin{array}{l}\text { 1) Algae } \\
\text { 2) Bacteria (0.4-2 } \\
\mu \mathrm{m}) \\
\text { 3) Microbial } \\
\text { Activities }\end{array}$ \\
\hline
\end{tabular}

From Location to location causes of emitter clogging varies. Each site requires different methods and different treatment to prevent the clogging. This study focuses on the physical parameters causing the emitter clogging. In various studies suspended particles have been blamed for most emitter malfunction. Various studies determine the causes of emitter clogging as large quantity of microscopic to sand size plastic materials and various silts.

A physical treatment that uses gravity to separate suspended solids from water is Sedimentation. It is widely used in first stage surface water treatment plant to remove particles causing turbidity after coagulation and flocculation. I water and waste water treatment s one of the oldest and most common problem is Suspended solids. Sedimentation is a very easy and reliable method to get rid of suspended solids. The efficiency of sedimentation is directly proportional to the surface area of sedimentation tank and its detention time. This makes the cost of sedimentation tank very high and the time required for the process is much. Certain techniques and advances are made to reduce the cost and detention time of the sedimentation process. One of the advanced techniques is high rate sedimentation, which reduces the detention time of settling device by reducing the distance of floc particles. The device is called as tube settlers. In these devices normally parallel plates and tubes are placed at an inclination to the horizontal. Tube settlers are multiple tubular channels sloped at a certain angle, related to each other which increase the settling area. Tube settlers reduce the average 1-4 hours of detention time to almost 20 minutes.
Turbid water is responsible for formation of media for microbial growth. These microbial growth may introduce include few viruses, bacteria, and parasites that can cause various clogging problems in a drip irrigation system. Irrigation water should have very less turbidity as turbid water may corrode the drippers, pipes etc. The heavy concentration of silt and soil get accumulated at the bottom pipe and pass through the drippers provided

In India, the dams and rivers are the sources of domestic water supply which carry heavy silt and soil concentration in the water. Many of the times in rainy season or a place where crushing industry or construction industry are located near sources of fresh water, water may carry huge quantity of fine particles. Fine particle contain crushed soil, cement powder, sand etc. If such water is being used for domestic purpose, huge quantity of mud gets settled on the floors of bathroom and toilet. Drainage pipes can also show blockage problem. Dishes or pots may leave the stains of mud when it washed by such muddy water. To solve this problem, the proposed technique will be very useful.

\section{LITERATURE REVIEW}

\subsection{General}

The intensive treatment of irrigation water required for the proper operation of drip irrigation systems is presently an accepted practice. To control emitter clogging, we need to know the basic causes of clogging. The major clogging factors have been identified and control measures developed to prevent emitter malfunction. All emitter clogging problems, however, have not been solved primarily because of cost. The main approach to control clogging is proper water treatment. The type of treatment is based on the quality of the irrigation water, which can be classified in terms of its physical, chemical and biological composition. The causes of emitter clogging and possible water treatment and preventive measures to maintain reliable operation are reviewed.

Sedimentation is a physical treatment process that utilizes to separate suspended solids from water by gravity. To reduce sedimentation costs several attempts have been made. One new advanced technique is high rate sedimentation, which reduces the detention time of settling device by reducing the distance of floc particles. In these devices normally parallel plates and tubes are placed horizontally or at an inclination at 600 angles to the horizontal. To increase treatment capacity of clarifier tube settler systems are not expensive remedy for drinking water and wastewater plants, that with the use of tube settler decrease operating costs, improve effluent water quality and reduce new installation footprints.

Constructed lightweight PVC tube settler is supported easily with minimum structures that effluent incorporates baffles and troughs. The settling capacity of rectangular sedimentation basins and or circular clarifiers increase with the use of tube settlers and parallel plates by reduce the vertical distance of floc particle are settle agglomerating to 
form particles of larger size. Tube settlers are use multiple tubular channels slope at a certain angle and related to each other, which combine and increased effective settling area. This provides for a settling depth of particle that is less than the settling depth and reducing settling times of a conventional clarifier unit. These devices are often using to enhance the performance of existing but overloaded sedimentation basins. The use of shallow depth settling basins enables the detention time of settling process to be reduced to only a few minutes in contrast to conventional settling basin designs which use 1 to 4 -hour detention.

\subsection{Research Papers}

S.Nakayama and D.A.Bucks: In this paper describe the major backdrop of Drip Irrigation i.e., the clogging of emitters and how it can be stopped. They discuss about various causes responsible for the emitter clogging such as blockage by microbes and even snails and also the major factor which is the quality of water. As the work on these operations improved and went two ways, one being hydraulic improvement of emitters and the other on the studies regarding clogging of these emitters, the studies in the field of clogging of emitters resulted in various outcomes regarding the treatment of this problem. Three of those treatments are 1.Water treatment for clogging of emitters. 2. Physical treatment, which involved filtration stations. 3. Chemical treatment, in which chemical water treatment such as Chlorination. These treatments are also to be selected according to the regional factors as the outcome of them might vary depending on these factors.

Nassim Al-Abed et al., 2007: In this paper they have studied the problem of the irrigation water Total Suspended Solid (TSS) on a farm in the Northern Jordan Valley, Jordan. They have performed the experiment on two different fields to estimate the efficiency of the procedure applied for irrigation network flushing. Here they compared a good managed and regularly flushed block (block A) with the block managed by the farmer (block B). It showed a reduction in the amount of sediments in the laterals and sediments built-up started at emitter number 56 along the lateral in block A compared to emitter 26 in block B. In the second experiment it was confirmed that flushing was needed on farm level. The result of this study provided a suggestion that to install a collection line that connects all lateral ends to one outlet, so that it becomes easy to the farmers for flushing TSS and also save their time. Due to regular flushing, it was found that suspended solids concentration was decreased within the network. The study concluded that flushing the sediments from the system was necessary so it helps in preventing the clogging of emitters.

Muharrem Yetis Yavuz, Kursad Demirel, Okan Erken, Erdem Bahar and Merve Devecileret al. ,2010: In this research paper they have studied 'Emitter clogging and effects on drip irrigation systems performances' i.e. how the emitter in irrigation gets affected due to clogging and affects its performance. Emitter clogging, which is formed in a short time due to irrigation systems' running under an inadequate pressure or owing to water quality, not only negatively influences uniformity of water distribution but also causes inadequate irrigation. In this survey, the clogging level determination of the emitters used in drip irrigation systems of some agricultural farms situated in Canakkale and their effects on irrigation performances were observed. The emitters were obtained from different farms in the investigated area, and were tested under the pressures of $50,100,150,200,250,300 \mathrm{kPa}$ in hydraulic laboratories. As a result it was found that Coefficient of variation of emitters along two of the laterals used two years and all of those used three years remained out of $5 \%$ limitation.

Avishek Shaw,Uddipta Ghosh and Ranajit Kumar Biswas have studied about 'Clogging Problem of Drip Irrigation Systems and its Remedies', In this research paper they describe Drip irrigation is the most efficient way of irrigation But Clogging is one of the most important problems encountered in this irrigation system which significantly reduce the efficiency of the system which consequently may encounter severe economic consequences in terms of the system operation, maintenance and the ultimate goal for sustainable crop production. They performed an experiment; the experiment was conducted at the Soil and Water Engineering Laboratory under the Faculty of Agricultural Engineering, Bidhan Chandra Krishi Viswavidyalaya, Nadia, and West Bengal during the period of 2015-16. The lateral contained 94 emitters of nominal discharge $4.0 \mathrm{lph}$. However, the newly used emitters gave the average discharge of $4.18 \mathrm{lph}$ at $1.05 \mathrm{~kg} / \mathrm{cm} 2$ pressure. The emitters were nonstop operated for 29 days and the reduction of discharges for clogging for each and every emitter was determined at 0,8 , 15 and 29 days interval. Chlorination was performed by injecting bleaching powder in a $300 \mathrm{ml}$ of water for 30 minutes. After performing chlorination, the discharges were measured at 1, 3,6 and 9 days interval to evaluate the performance of chlorination on clogging. The improvements of discharges of the emitters were found about 14 and $23 \%$ in 3 and 6 days respectively after chlorination. It was also found that there is no improvement of chlorination after 6 days.

\footnotetext{
Takuma Matsuo, Yuta Mizuno and Hideo cho "Monitoring of pipe clogging by mussels utilizing an optical fibre AE system" (2009) Clogging of pipes caused by bivalves such as mussels is a serious problem preventing safe operation of plants. Effective early detection of mussel clogging was studied using an optical fibre AE system. This system was developed to detect minimum flow velocities when AE signals are generated from mussels. First, a sheet-type optical fibre sensor was developed for the detection of cylinder-wave AE signals from mussels. The sensor was used by winding it around a pipe. The frequency response of $13 \mathrm{kHz}$ to $27 \mathrm{kHz}$ from the developed sensor depended on its width. AE signals from living mussels attached on the inside surface of PMMA pipes were monitored next. The flow velocity when the first AE signal was detected increased depending on the
} 
shell-fish size. AE signals were produced by mussels that were more than $11 \mathrm{~mm}$ long. AE signals from mussel colony were than monitored. The flow velocity, when the first AE signal was detected, was also dependent on shell size. However, the flow velocity was lower than that of the single mussel test and mussels that were less than $5 \mathrm{~mm}$ produced AE signals. Additionally, the flow velocity decreased linearly with the shell length of colony members. Researchers identified the minimum mussel size for $\mathrm{AE}$ detection for a given flow velocity.

Muharrem Yetis Yavuz, Kursad Demırel, Okan Erken, Erdem Bahar and Merve Deveciler "Emitter clogging and effects on drip irrigation systems performances" (2010) Emitter clogging is one of the most important factors that affect the performances on drip irrigation systems. Emitter clogging, which is formed in a short time due to irrigation systems' running under an inadequate pressure or owing to water quality, not only negatively influences uniformity of water distribution but also causes inadequate irrigation. In this survey, the clogging level determination of the emitters used in drip irrigation systems of some agricultural farms situated in Canakkale and their effects on irrigation performances were observed. The emitters were obtained from different farms in the investigated area, and were tested under the pressures of $50,100,150,200,250,300 \mathrm{kPa}$ in hydraulic laboratories. The clogging extend of emitters, flushing of clogging increased pressure and also performance values as coefficient of variation $(\mathrm{Cv})$ under $100 \mathrm{kPa}$ pressure, statistical uniformity (Us), emission uniformity (Eu) and Christiansen's uniformity coefficient $(\mathrm{Cu})$ were established through the tests. Acquired performance values must be matched with emitter performances that have not been used in irrigation. As a result of the study it was determined that some emitters are plugged on laterals used for 2 or 3 years in consequence of the tests. It as also determined that emitter coefficient of variation varied in the ranges of 0.43 and $0.63,0.43$ and $0.69,0.48$ and $0.58,0.56$ and 0.73 for unused emitters, for one year, for two years and for three years used emitters. Coefficient of variation between emitter flows remained within the limit of $5 \%$ in all laterals, except for one of the laterals used for one year. Coefficient of variation of emitters along two of the laterals used two years and all of those used three years remained out of 5\% limitation. Similar results to $\mathrm{CVm}$ (manufacturing variation coefficient) were determined for performance parameters in respect of statistical uniformity (Us), emission uniformity (Eu) and Christiansen's uniformity coefficient $(\mathrm{Cu})$.

Amod gujar, Mangesh Borkar, Dr.A.G. Bhole, Payal Baithule, 2017: In this research importance of sedimentation as a physical treatment to separate Total Suspended Solids from water is discussed. The advantages and disadvantages of sedimentation as a process are listed. The study is aimed to emphasize the performance of a tube settler unit. To do so a pilot scale model is prepared. The setup is designed and fabricated with MS sheet and installed at the water treatment plant in Nagpur region. The size and shape of tube is $1 \mathrm{~mm}$ in thickness and having a square section of $5 \mathrm{~cm}$. The area of each tube section is $25 \mathrm{~cm} 2$. There are total 6 numbers of tubes having an inclination of 60 degree. After installing the pilot scale model in the water treatment plant turbidity test was carried out with the help of Nephlo Turbidity Meter. The results showed that that the average efficiency of turbidity removal is $70-80 \%$ which is more than the conventional sedimentation tank.

Kshijija balwan, aarju Mujawar, Manisha Karkhe, 2016: Conducted a pilot scale model and installed it at Ichalkaranji municipal water treatment plant the effect of length and inclination of tube settler on the flocculated water was studied. 3 tubes of length $40 \mathrm{~cm}, 50 \mathrm{~cm}, 60 \mathrm{~cm}$ were studied having an inclination of 45 degrees and 60 degrees. The surface overflow rate was kept similar as that of a conventional clarifier i.e. $35000 \mathrm{Lit} / \mathrm{m}^{2} / \mathrm{hr}$. The turbidity test was carried out with the help of Nephlo Turbidity Meter. From the study it was concluded that turbidity is directly proportional to the length of tubes. Out of the 6 combinations the optimum result was observed for the length $60 \mathrm{~cm}$ and an inclination of 45 degrees.

\subsection{Findings from the literature review}

- Drip/Trickle irrigation system is the most efficient than all. Water is applied close to the plants so that only part of the soil in which the roots grow is wetted, unlike surface and sprinkler irrigation, which involves wetting the whole soil profile.

- Emitter clogging is one of the severe drawback of Drip Irrigation System

- Causes of water clogging and not only physical but chemical and biological also.

- The most Common physical problem is Total Suspended Solids

- Sedimentation is a very effective process to remove the total suspended solids

- Major drawback of sedimentation process is high Detention time

- Tube Settlers enhance the sedimentation process and have an efficiency of around $90 \%$ 


\section{METHODOLOGY}



Figure 1: Water Storage Tank with inclined tube like structure

The fine particles suspended in water can be settle and removed in water storage tank. The design of water tank is shown in Fig no. 1. The planned tank design contains two concentric tanks. Let small diameter Inner tank is A and outside larger diameter tank is B. Inlet of water tank is provide at the top of tank B. Water drop from inlet pipe in tank B and water level start rising in tank B.

Inclined tube like structures is provided at height of $\mathrm{h} \mathrm{m}$ from the bottom of tank B. Another end of inclined tube like structure open in tank $\mathrm{A}$ it height $\mathrm{H}$ m from bottom of tanks. Fresh water can be removed from fresh water pipe provided at bottom of tank A.

As the water will rise in tank B, it will rise up to the height $\mathrm{h} \mathrm{m}$ from bottom and water will start entering in the inclined tube like structure. The water level will gradually increase in tank B and inclined tube like structure. When the water will rise above the height of $\mathrm{H} \mathrm{m}$ from the bottom of tank then it will fall in tank A. No water level will increase in tank B by the time of water level will be more than height $\mathrm{H} \mathrm{m}$ in tank A. As the water level in tank B and tank A will be above height $\mathrm{H} \mathrm{m}$, both the tank will show same rise of water.

According to the principle of specific gravity of different materials, water has low specific gravity than fine settling material. When water start rising in inclined tube like structure, the fine particles settle due to higher specific gravity and slides in tank B. Sludge material settle in tank $\mathrm{B}$ and can be remove by sludge removal pipe provided at bottom in tank B.
When water (above height $\mathrm{H} \mathrm{m}$ in tank B) will start falling, suspended particles also come down with some settling velocity and get accumulate at the base of tank B without entering it in inclined in tube like structure.

The slope provided at bottom of outside tank B can provide at the center of sides of inlet pipe and inclined tube like structure. The sludge removal pipe is provided where the tank B have lowest slop.

The outlets provided to existing water storage tanks in houses is around 6-8" above from the bottom. The efficiency of removing sludge will be more for the same volume of dead water.

\section{CONCLUSIONS}

- Drip Irrigation system is an effective system to conserve water

- Emitter clogging is a major drawback of drip irrigation system

- Helpful for increasing the efficiency of drip irrigation system

- This concept will help to reduce the work load of farmer.

- This idea will help in fulfilling government aim "Per Drop, More Crop."

- Around $70 \%$ of turbidity can be removed by using this model

- This method will help to increase the life span of drips

- This method can help farmers to prevent the clogging of emitters from Physical parameters.

\section{REFRENCES}

[1] Muharrem Yetis Yavuz, Kursad Demirel, Okan Erken, Erdem Bahar and Merve Deveculer "Emitter clogging and effects on drip irrigation systems performances”, pp.532-538 , African Journal of Agricultural Research Vol. 5,April 2010.

[2] Kshitija Balwan, Aarju mujawar, Dhanashri Bhabuje, Manisha karake "Study of the Effect of Length and Inclination of Tube settler on the Effluent Quality", International Journal of Innovative Research in Advanced Engineering (IJIRAE) ISSN: 2349-2763 Issue 01, Volume 3 (January 2016).

[3] Takuma Matsuo, Yuta mizuno and Hideo cho "Monitoring of pipe clogging by mussels utilizing an optical fiber AE system", Faculty of Science and Engineering, Aoyama Gakuin University, Japan, (2009)

[4] Anchit Garg, Priyamitra Munoth, Rohit Goyal "Application of soil moisture sensors in agriculture: A review" PP163-98 Proceedings of International Conference on Hydraulics, Water Resources and Coastal Engineering (Hydro2016), CWPRS Pune, India ,December 2016.

[5] Avishek Shaw, Uddipta Ghosh and Ranajit Kumar Biswas "Study on Clogging Problem of Drip Irrigation Systems and its Remedies", Department of Soil and Water Engineering, Bidhan Chandra Krishi Viswavidyalaya, Mohanpur, Nadia, West Bengal741252, India, 2018.

[6] Hasnulhadi Jaafar, Muhamad Azwan Roslan, Muhamad Safwan Bin Muhamad Azmi, "Blockage Detection in Circular Pipe Using Vibration Analysis", School of Mechatronic Engineering, University Malaysia Perlis, Malaysia, Vol. 2 (2012) No. 3 ISSN: 2088-5334, International Journal on advance engineering Information Technology. 
[7] Ömer Faruk KARACA and Kenan UCAN, "Elimination of lime causing clogging in emitters by chemical methods in drip irrigation" pp.1136-1143 Department of Biosystems Engineering, Faculty of Engineering and Architecture, University of Bozok, 66200 Yozgat, Turkey. Vol. 8(13) , Academic Journals, 11 April, 2013

[8] Amod Gurjar, Mangesh Bhorkar, Dr. A. G. Bhole , Payal Baitule , "Performance Study of Tube Settlers Module" pp.52-55 Int. Journal of Engineering Research and Application, Vol. 7, Issue 3, ( Part -6) March 2017.

[9] E S. Nakayama and D. A. Bucks, "Water quality in drip/trickle irrigation" , US Water Conservation Laboratory, 4331 East Broadway, Phoenix, AZ 85040, USA, Irrig Sci (1991) 12:187192, Springer-Verlag 1991.
[10] Lili Zhangzhong, Peiling Yang, Wengang Zheng, Caiyuan Wang, Chong Zhang and Minglei Niu , "Effects of Drip Irrigation Models on Chemical Clogging under Saline Water Use in Hetao District, China", National Engineering Research Center for Intelligent Equipment in Agriculture, Beijing Academy of Agriculture and Forestry Sciences, Beijing 100097, March 2018. 